\title{
Influence of Rehydration on Changes in Hydration Biomarkers and Blood Sugar Stability
}

\author{
Rodhi Hartono ${ }^{1 *}$, Arwani ${ }^{2}$, Elisa ${ }^{3}$, Iis $\mathrm{S}^{4}$, Supriyadi ${ }^{5}$ \\ 1,2,3,4,5 Nursing Department, Poltekkes Kemenkes Semarang, Jln. Tirto Agung Pedalangan, Banyumanik, \\ Indonesia
}

*Corresponding Author: Rodhi Hartono, Department of Nursing, Poltekkes Kemenkes Semarang, Jln. Tirto Agung Pedalangan, Banyumanik, Indonesia, E-mail: Gusrodh@yahoo.com

\begin{abstract}
Background: Dehydration has an impact on cognitive, physical functioning that can affect a person's mood.

The Objective: This study aims to determine the effect of rehydration giving of watermelon juice, coconut water, wine palm water and isotonic drinks orally to hydration biomarker changes and blood sugar stability on isotonic dehydration case after physical exercise.
\end{abstract}

Method: This type of research is a pre-experimental study with a one-group pretest-posttest design. In this design, a pretest is administered before treatment and post-test after treatment. The variables in this study are the consumption of eating various foods and the behavior of physical activity measured before and after being given nutritional counseling.

Result: The results showed that the means rehydration of isotonic drinks gave the most dominant influence in the stability of blood sugar and watermelon juice gave the lowest effect in the stability of blood sugar. Isotonic drinks rehydration has the most rapid effect on pulse rate and oral rehydration. Juice Watermelon gives the slowest effect on the return of respondent's pulse frequency.

Conclusion: Proper oral rehydration selection is important that people with mild to moderate dehydration immediately experience a return of stamina fluid volume.

Keywords: Oral rehydration, Hydration biomarker, Blood glucose

\section{INTRODUCTION}

Common dehydration due to daily activities is isotonic dehydration that occurs due to fluid loss equal to the concentration of sodium in the blood. To replace the fluid that comes out of the body along with the electrolyte ions present therein it is preferable when drinking water contains an ion corresponding to the ion that has been removed.

Recent years have emerged the phenomenon of isotonic beverage companies as drinks that are able to replace the body ions, even isotonic drinks are considered to increase concentration, to maintain skin moisture, and to restore the energy began to decline. Isotonic drinks are considered to be better than regular drinking water because regular drinking water has no mineral content such as isotonic drinks (Handayani Fransiska, 2016).
The rapid development of media for the promotion of beverage products and in line with the opening of the ASEAN Economic Community making it is necessary to conduct research that will provide information to the public in choosing the right type of drink for rehydration.

Various oral rehydration in Indonesia found including watermelon fruit which is one of the most widely consumed fruits in Indonesia.

Coconut water has great potential into a rehydration drink for good nutritional content, rich in nutrients, namely sugar, protein, fat and relatively complete so it is good for the growth of bacteria producing food products. The fruit of palm wine has excellent nutritional content such as sugar content of $10.96 \%$, water content $87.78 \%$, protein $0.28 \%$, fat $0.02 \%$. Juice of wine palm or locally known as legen is very easily contaminated because it contains complete 
nutrients such as sugar, protein, fats and minerals that are very good for microbial growth. As such, the hypothesis discussed in this study: "is there any influence of giving rehydration of watermelon juice, coconut water, isotonic drinks, palm wine water per oral hydration against biomaker changes and blood sugar stability in case of dehydration isotonic after physical exercise?"

\section{Materials And Methods}

This study is a non-randomized controlled quasi experiment with a pre-test and post-test group design with controlled group. In the control group and intervention was given treatment in the form of physical exercise of running around the field $( \pm 1 \mathrm{~km})$. Rehydration of fluid is done 5 minutes after running. In the control group was given 3 times the drinking of Aqua 350 $\mathrm{ml}$, (Treatment I): $350 \mathrm{ml}$ watermelon juice (Treatment II):coconut water $350 \mathrm{ml}$ (Treatment III): $350 \mathrm{ml}$ wine palm water (Treatment IV): $350 \mathrm{ml}$ Pocari Sweat (Treatment V). Each group was measured the value of Hydration biomaker (Hematocrit, blood sugar, urine type weight, Mean Arterial Pressure and pulse rate).

The population in this study is 46 nursing department students with purposive sampling resulting in the number of samples for each group of 7 respondents.

Data collection tool used in this research is tensimeter and stethoscope for Mean Arterial Pressure (MAP) measurement, watch with second hand for counting pulse, Stick Gluco Test set to detect respondent's blood, bottle \& urine sample and $3 \mathrm{cc}$ syringe for examination of blood hematocrit values.

Data analysis was done with univariate analysis to interpret frequency distribution covering data concentration and dissemination. Dependent $\mathrm{t}$ Test, Mann Whitney and Wilcoxon test were employed to examine the difference effect of each treatment.

\section{RESULT AND DISCUSSION}

Research respondents in all groups were women at 18 years of age. One of the factors affecting fluid and electrolyte balance is age, ambient temperature, diet, activity, and stress or disease (Sherwood, 2001). The age of the female respondents is very homogenous at 18 years old (middle adolescent). The results showed an increase in Hematocrit value from before treatment and after running $1 \mathrm{~km}$ and Hematocrit value decreased again after the respondent was given oral rehydration according to the group. The group that showed the highest decrease in Hematocrit value was the oral rehydration group of watermelon juice with 2.58 difference of Hematocrit value when running with Hematocrit value after oral rehydration. The group with the lowest decrease in Hct value is oral rehydration of coconut water. Hematocrite (Hct) is the percentage of all erythrocyte volume separated from plasma by rotating in a special tube with time and velocity with a value expressed in percent (\%). Normal values of Hct in men is 40-48 \% and in women $35-43 \%$. Hct value is an indicator of a person experiencing dehydration, normohydration or overhydration.

The normal value of blood sugar level is 70 $200 \mathrm{mg} / \mathrm{dl}$. The results showed a decrease in blood sugar level after the respondents underwent a $1 \mathrm{~km}$ running activity and decreased after 30 minutes on oral rehydration. The value of GDS decrease after oral rehydration was oral rehydration group Pocary Sweat (4 digits) and watermelon juice group was the group that experienced the highest decrease in blood sugar level of 8 digits.

Specific gravity of urine values in all groups increased after $1 \mathrm{~km}$ running. Normal values of urine specific gravity ranged from 1.015 to 1.025. The increase shows the tendency of respondents experiencing dehydration. Oral rehydration given has not been able to reduce the dehydration level.

Assessment of the MAP value shows an increase in MAP value after running and decreasing MAP values after oral rehydration. Only the Pocary Sweat oral rehydration group experienced elevated MAP values after 30 minutes of oral rehydration. In harmony with the pulse frequency results showed that all groups experienced an increase in pulse frequency after a $1 \mathrm{~km}$ running treatment and decreased pulse frequency after 30 minutes of oral rehydration. The largest decrease in pulse frequency after oral rehydration (22.86 digits) was the Oral Pocary Sweat rehydration group and the slowest decline (18 digits) pulse frequency was the oral rehydration group of wine palm water.

Bivariate analysis test of Dependent $t$ test for Hematocrit value describes no difference of hematocrit value in oral rehydration group Aqua, wine palm and coconut water with $\mathrm{p}>$ 0.05 value while oral rehydration group of watermelon juice and Pocary Sweat have $p$ 
value $<0.05$ which means there is a difference in hematocrit values between after running and after oral rehydration. There were differences in blood sugar levels in the oral rehydration group of Aqua, wine palm and coconut water, watermelon juice and Pocary Sweat with a value of $p<0.05$ which means there is a difference in blood sugar level between after running and after oral rehydration. The lowest $\mathrm{p}$ value $(0.006)$ is in the coconut oral rehydration group. Wilcoxon test results showed no difference in specific gravityUrine before and after oral rehydration ( $p>0,05)$. Dependent t test test data did not have difference of MAP value in Aqua, Water of wine palm, Coconut Water, Watermelon juice and Pocary Sweat rehydration group with $p>0,05$. Bivariate analysis test of Dependent $t$ test for frequency of pulse value describes there is difference of value of pulse frequency in oral rehydration group Aqua, Coconut Water, Watermel on juice and Pocary Sweat with $\mathrm{p}$ value $<0.05$ whereas oral rehydration group wine palm has $p>0,05$ which means there is no difference in the value of the pulse rate between after running and after oral rehydration.

The test result of Independent $t$ test $\mathrm{p}=0.324$ (> $0,05)$ showed no difference between hematocrite value, MAP, blood sugar level, urine specific gravity and pulse frequency in oral rehydration group of Aqua, watermelon juice, water of wine palm, coconut water and Pocary Sweat. The anova test was performed only in the category of blood sugar level and the frequency rate of the pulse because the $t$ test results of the dependent test were only those categories which had $\mathrm{p}<0.05$.

Dependent $t$ test results showed no difference in hematocrit values in the oral rehydration group of Aqua, water of wine palm and coconut with a value of $p>0.05$ whereas the oral rehydration group of watermelon juice and Pocary Sweat has a value of $\mathrm{p}<0.05$ which means there is a difference in hematocrit values between after running and after oral rehydration. Nevertheless the means value shows the tendency of an increase in Hct value after a $1 \mathrm{~km}$ running and a decrease in Hct value returns after the respondent is given oral rehydration according to the group. The group that showed the highest decrease in Hct value was the oral rehydration group of watermelon juice with 2.58 difference of Hct value when running with Hct value after oral rehydration. The group with the lowest decrease in Hct value was oral rehydration of coconut water. In accordance with Benardot's
(2006) opinion, drinking potassium containing high concentrations may delay plasma recovery longer (more than 90 minutes) than sodiumcontaining beverages. Coconut water is a drink containing high potassium $(6.02 \mathrm{~g} / \mathrm{L})$, so it is possible to slow the recovery of plasma volume through the indicator of hematocrite value. Watermelon is a fruit that contains high Flavonoid and Potassium $80 \mathrm{mg} / 100 \mathrm{~g}$ lower than coconut water. Both substances are factors that can inhibit the reabsorption of water and sodium in the tubules and increase the exchange of $\mathrm{Na}$ and $\mathrm{Cl}$ more actively so as to facilitate the process dieresis / increased urine volume. Normal blood sugar value is $70-200 \mathrm{mg} / \mathrm{dl}$ and one's blood sugar will decrease when someone is undergoing repetitive activity / sport. The results showed a decrease in blood sugar level after the respondents underwent a $1 \mathrm{~km}$ run and decreased after 30 minutes of oral rehydration. The lowest decrease value after oral rehydration was oral rehydration group of Pocary Sweat (4 digits) and watermelon juice group was the group that experienced the highest decrease in blood sugar level of 8 digits.

The results of the Lusi Putri study (2015) showed rehydration drink of coconut water returned body weigHct and hematocrite to normal 2 hours compared with the rehydration of white water and supplement drink. Coconut water is a natural drink containing electrolytes and natural sugars that can overcome dehydration. The content of electrolytes and sugars in rehydrated drinks can also affect the volume of urine produced. Rehydration drinks should not induce urinary expenditure or induce minimal urine formation because urine volume also contributes to reduced plasma volume.

Wilcoxon test test results showed no difference urine specific gravity before and after oral rehydration ( $>0.05)$ even though there is a tendency to increase the value of means per group after running $1 \mathrm{~km}$. Normal values of urine specific gravity ranged from 1.015 to 1.025. The increase shows the tendency of respondents experiencing dehydration. Oral rehydration given has not been able to reduce the dehydration level of respondents. This is due to the rehydration volume of $350 \mathrm{ml}$ which is not sufficient for the fluid needs of respondents.

The results showed that all groups experienced an increase in pulse rate after $1 \mathrm{~km}$ treatment and decreased pulse frequency after 30 minutes of oral rehydration. The largest decrease in pulse frequency after oral rehydration (22.86 digits) 
was the oral Pocary Sweat rehydration group and the slowest decline (18 digits) pulse frequency was the oral rehydration group of wine palm water. This is possible because Pocary Sweat drinks have a composition similar to blood plasma fluid containing a balanced electrolyte. The higher the electrolyte content in the beverage the greater the absorption of the intestine so that the plasma volume condition returns to balance which will eventually lead to a decrease in heart contraction (Guyton \& Hall, 2000).

The result of ANOVA analysis of blood sugar level value generates $p$ - value $<0.05$ which means there is difference at least two different measurements between and before treatment, 5 minutes after running and 30 minutes after oral rehydration. Furthermore, Pairwise Comparisons test result showed significant difference only in group 5 minutes after running with 30 minutes after oral rehydration with $\mathrm{p}$ value of 0.000 .

ANOVA analysis of pulse frequency produced p-value $<0.05$ meaning that there is difference between at least two different measurements between pulse frequency before treatment, 5 minutes after running and 30 minutes after oral rehydration. Also, Pairwise Comparisons test show the differences obtained in the third / all measurements with $\mathrm{p}$ value of 0.000 .

\section{CONCLUSION}

There is no difference effectiveness in oral rehydration of Aqua, wine palm water, coconut water, watermelon juice and Pocary Sweat as the $\mathrm{p}-$ value is $>0.05$. However, descriptively, there is a tendency that Pocary Sweat rehydration gives the most dominant influence in blood sugar stability and watermelon juice gives the lowest effect in stability of blood sugar. Also Pocary Sweat rehydration provides the most rapid effect on pulse rate decrease and oral rehydration. In another side, watermelon juice has the slowest effect on the return of the frequency of the respondent's pulse.

\section{REFERENCES}

[1] Benardot D (2006). Advanced Sport Nutrition. United Graphics. Champaign. 75-100.

[2] Guyton \&amp; Hall (2000), Review of Medical Physiology, Philadelphia; Lippincott.

[3] Handayani Fransiska, (2016). Pengaruh Aktivitas Berlari terhadap Tekanan Darah dan Suhu pada Pria Dewasa Normal. FK Universitas Sam Ratulangi. Manado.

[4] Lusi Putri., Lia Amalia., Maria Immaculata., dkk. (2015). Pengaruh Rehidrasi Menggunak Air Kelapa (Cocos Nucifera L) Terhadap Stamina Atlet Dayung. Universitas Prof. Dr. HAMKA. Bandung.

Citation: Rodhi Hartono, Arwani, Elisa, Iis S, Supriyadi. Influence of Rehydration on Changes in Hydration Biomarkers and Blood Sugar Stability. ARC Journal of Nutrition and Growth. 2017;3(2):1-4. doi:dx.doi.org/10.20431/2455-2550.0302001.

Copyright: () 2017 Authors. This is an open-access article distributed under the terms of the Creative

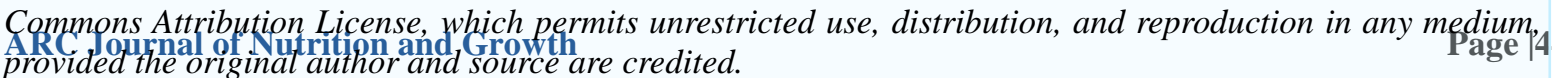

